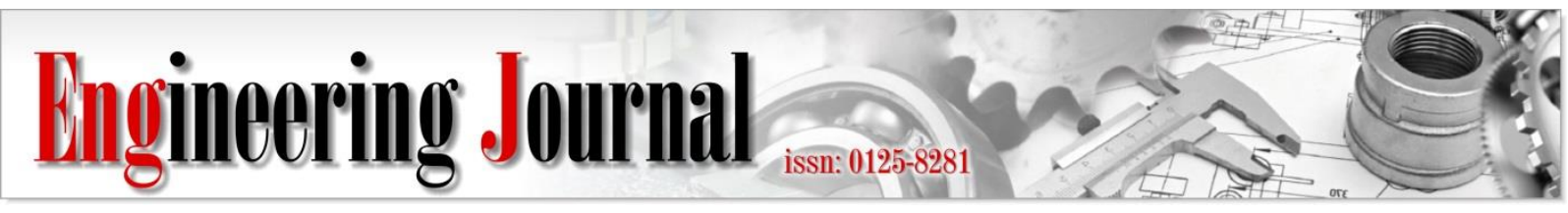

Article

\title{
Modeling of Precast Concrete Load-Bearing Walls Exposed to Fire
}

\author{
Thanyawat Pothisiri ${ }^{1, \mathrm{a}}$, Pitcha Jongvivatsakul ${ }^{2, \mathrm{~b},{ }^{*}}$, Soklin Chou $^{3, \mathrm{c}}$, \\ and Anil C. Wijeyewickrema ${ }^{4, d}$
}

1 Department of Civil Engineering, Faculty of Engineering, Chulalongkorn University, Phayathai Road, Pathumwan, Bangkok 10330, Thailand

2 Innovative Construction Materials Research Unit, Department of Civil Engineering, Faculty of Engineering, Chulalongkorn University, Phayathai Road, Pathumwan, Bangkok 10330, Thailand 3 Advancing Engineering Consultants, Ltd., No. 23 Street 294 Sangkat Tonle, Basac, Phnom Penh, Cambodia

4 Department of Civil and Environmental Engineering, Tokyo Institute of Technology, O-okayama, Meguro-ku, Tokyo 152-8552, Japan

E-mail: athanyawat.p@chula.ac.th, bitcha.j@chula.ac.th (Corresponding author),csoklin.chou@yahoo.com, dwijeyewickrema.a.aa@m.titech.ac.jp

\begin{abstract}
The performance of precast concrete load-bearing walls exposed to fire is investigated using 3-D thermal and structural models. The thermal model is validated by comparing the predicted temperatures with results from the fire tests carried out in the present study, previous experimental studies, and Eurocode 2. The structural model is validated by comparing the predicted displacements and crack patterns with results from the fire tests carried out in the present study. It is found that the results obtained from the thermal model and the structural model are in line with the experimental data and Eurocode 2 results. The validated 3-D model of precast concrete load-bearing walls is used to study the effect of load level, slenderness ratio and boundary conditions on the fire performance of the walls. The results show that the fire resistance rating of load-bearing walls decreases with increasing load level and slenderness ratio, while the fire resistance rating of the walls increases when rotational restraints are imposed at the ends of the walls. Finally, equations are presented for estimating the fire resistance rating of the walls with different support conditions.
\end{abstract}

Keywords: Fire resistance, precast concrete, load-bearing walls, finite element model.

ENGINEERING JOURNAL Volume 23 Issue 6

Received 22 October 2018

Accepted 29 October 2019

Published 30 November 2019

Online at http:/ /www.engj.org/

DOI:10.4186/ej.2019.23.6.433 


\section{Introduction}

Precast concrete load-bearing walls have been widely used in buildings with an intrinsic function as fireresisting elements. The role of a precast concrete load-bearing wall exposed to fire, is generally seen to be threefold. First, the wall must preserve its structural stability to prevent collapse of the building. Second, the wall is required to maintain its integrity, i.e. prevent the spread of flames from one side of the wall to the other side. Third, the wall must provide adequate insulation to prevent an excessive temperature rise on the unexposed face. The fire resistance performance of a reinforced concrete wall is affected by the thermal and physical properties of the materials (i.e., concrete and reinforcing steel), the location of steel rebars, the dimensions of the wall, the end restraints and the loading conditions.

Fire-resistance tests of light-weight concrete walls [1] have shown that such walls have a superior performance, when compared to normal-weight concrete walls in terms of yield load, ultimate load, crack load, stiffness, ductility and inter-story drift. Moreover, centrally reinforced walls behave better in fire than doubly reinforced walls with the same amount of reinforcement, while walls with smaller thermal bowing due to smaller in-plane load perform better than the walls with larger thermal bowing due to larger in-plane load [2-3]. The load-bearing capacity of reinforced concrete walls with one-sided fire exposure, reduces significantly with increasing slenderness ratio [4]. The thickness of the concrete wall has also been reported to significantly affect its fire resistance when exposed to fire on both sides [5]. Furthermore, a rotational restraint at the top end and a pin at the bottom end of a wall provide more beneficial effects in reducing the lateral displacement, hence, increasing the fire resistance, as compared to having pins at both the top and bottom ends [4]. On the other hand, cantilever walls may show larger deflections as a result of thermal bowing and P-delta effects [6].

Previous studies on modeling of reinforced concrete walls at elevated temperature are still limited. Most of the proposed models have been developed in two dimensions [2, 4-5]. As such, the out-of-plane structural behavior of load-bearing concrete walls exposed to fire cannot be thoroughly examined and the application of these models may be limited. Previous studies have also investigated the response of RC beams [7-8], RC slabs [9], RC columns [10-12], composite beam-slab assemblies [13] and bridge girders [14] exposed to fire using finite element simulations.

In the present study, a three dimensional model of precast concrete load-bearing walls exposed to fire is developed using the finite element program ANSYS [15]. Load-bearing fire tests of two full-scale precast concrete walls conducted by Pothisiri et al. [16] were used to validate the efficacy of the proposed model by comparing the measured data with the predicted temperatures, displacements and crack patterns. The model is used to study the effect of load level, slenderness ratio and support conditions on the fire performance of walls. Equations are obtained for estimating the fire-resistance rating of the walls with different support conditions.

\section{Finite Element Modeling of Precast Concrete Walls Exposed to Fire}

A 3-D finite-element model is developed in this study to investigate the thermo-mechanical behavior of precast concrete load-bearing walls exposed to fire using ANSYS [15]. The analyses are carried out in two stages. In the first stage, a thermal analysis is performed, where the experimental fire curve based on the ISO 834-1 standard [17] is adopted for the nodal temperature on one side of the wall in the form of load steps. Each load step consists of several sub-steps that are solved using the Newton-Raphson technique [18]. In the second stage, a structural stress analysis is carried out in order to predict the performance of the wall subjected to an applied axial load and the temperature history obtained from the thermal model.

\subsection{3-D Thermal Model of the Wall}

The thermal model requires transient heat transfer calculations to evaluate the temperature distribution within the wall. The load steps are specified in time increments of $60 \mathrm{~s}$. The thermal model of the reinforced concrete wall investigated in the current study, comprises three dimensional solid elements for concrete and link elements for steel rebar. The time-temperature curve taken from the fire tests in accordance with ISO 834-1 [17] is applied on one side of the wall. Convection is also taken into account on the unexposed side of the wall (with a heat transfer coefficient of $9 \mathrm{~W} / \mathrm{m}^{2} .{ }^{\circ} \mathrm{C}$ ), while the four edges of the wall are insulated by ceramic fiber. Note that insulation is imposed automatically in ANSYS when no thermal condition is specified along 
a boundary [15]. The non-specified boundary conditions on the four edges of the wall result in insulated edges. The thermal loads and boundary conditions of the walls are shown in Fig. 1.

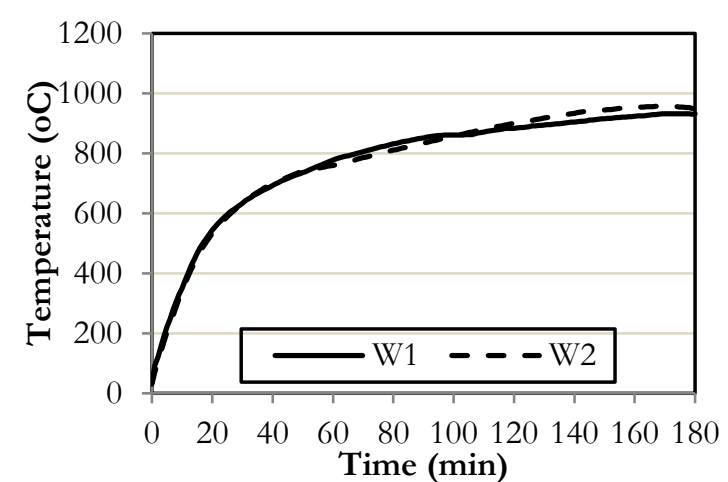

(a) Exposed face temperature

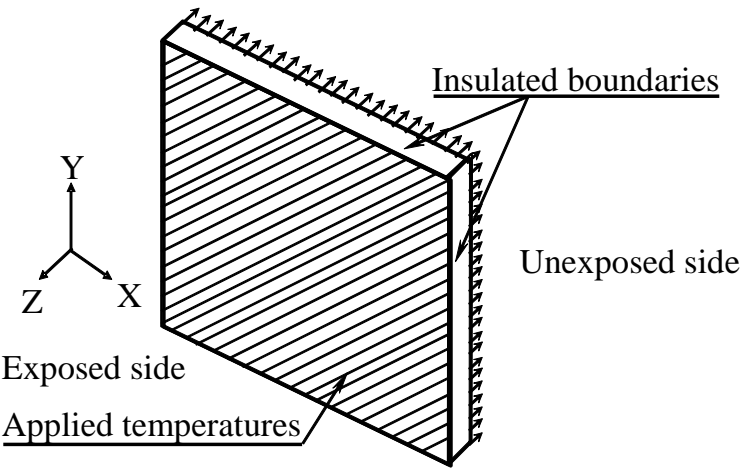

(b) Specified loads and boundary conditions

Fig. 1. Input parameters for the thermal model of the wall.

According to Franssen et al. [19] and Buchanan [20], the dominant heat transfer mode within the test furnace from the fire nozzles to the structure inside the fire chamber is radiation. However, in the actual fire tests, the fire nozzles in the furnace are in close proximity to the tested walls, hence, the exposed face temperatures which are measured by using thermocouples, are used as input temperatures in the thermal model as shown in Fig. 1.

In the thermal analysis, concrete is modeled using the SOLID70 3-D thermal conduction eight node element with a single degree of freedom (i.e., temperature) at each node. The steel rebar is modeled using the LINK33 3-D two node uniaxial element with the ability to conduct heat between its nodes. The element is characterized by a cross-sectional area and the material properties. The thermal conductivity is in the element longitudinal direction [15]. FE 3D meshes with different levels of refinement are used to investigate the convergence of numerical solutions. A FE mesh of the wall with 31,376 elements was found to yield convergent numerical results and is used in the present study. It is determined that the finite element model of the wall with 31,376 elements gives reasonably accurate results and is therefore used in the subsequent investigations.

The thermal properties of concrete and steel rebar required in the thermal model are thermal conductivity, specific heat and mass density. Concrete is a non-homogeneous, anisotropic medium composed of particles of aggregates mixed with hydrated cement paste. For simplicity, concrete can be considered as a homogeneous isotropic material in heat transfer analysis. The temperature-dependent thermal properties of concrete (i.e., thermal conductivity $k_{c, T}$, specific heat $c_{c, T}$, and mass density $\rho_{c, T}$ ), employed in the proposed implementation scheme are taken from Eurocode 2 [21] and shown in Fig. 2. The thermal properties of steel rebar (i.e., thermal conductivity $k_{s, T}$, specific heat $c_{s, T}$, and density $\rho_{s, T}$ ) used in the thermal model are based on Eurocode 3 [22] and also shown in Fig. 2.

It should be noted that the effect of concrete spalling - in which the cross-sectional area of the wall can be reduced due to concrete falling-off - is not taken into account in the proposed model. Therefore, the applicability of this model is limited to concrete walls with negligible amount of spalling, e.g. those with polypropylene (PP) fibers in the concrete mixture [23 - 30]. The addition of PP fibers to the concrete mixture in precast load-bearing walls to prevent spalling, is not the usual practice for low-rise buildings, but perhaps appropriate for high-rise buildings to provide a higher fire resistance rating.

\subsection{3-D Structural Model of the Wall}

The structural model is used to predict deflections, internal forces and crack patterns of the walls due to the applied load and temperatures from the thermal analysis. The temperatures are input as thermal body loads. The axial load is applied gradually to minimize inertia effects since the analysis is explicit dynamic, before the thermal load is applied. 


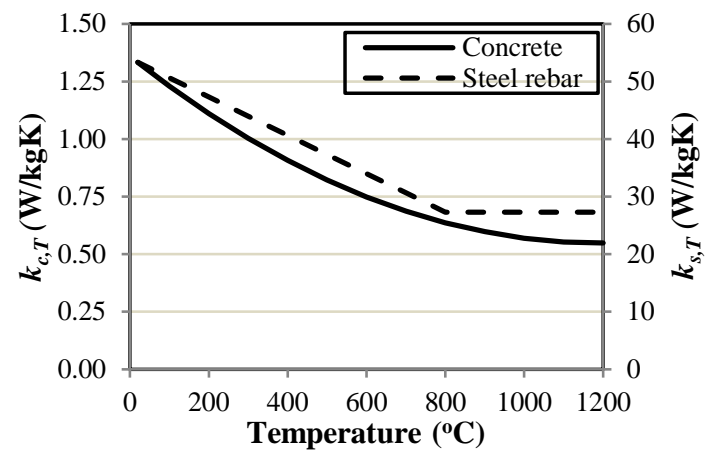

(a) Thermal conductivity

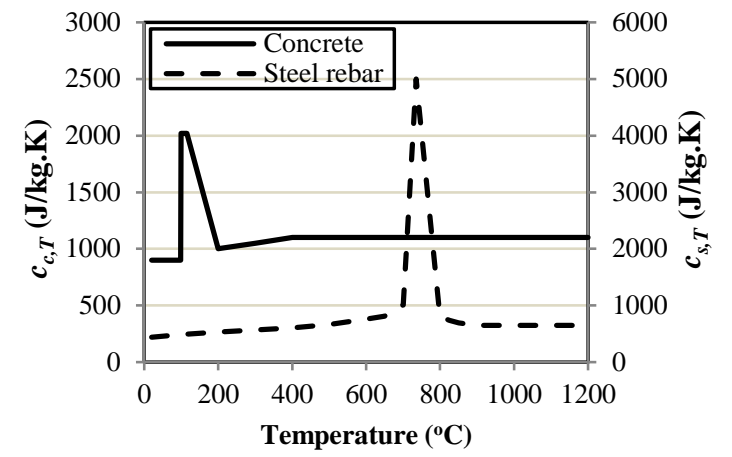

(b) Specific heat

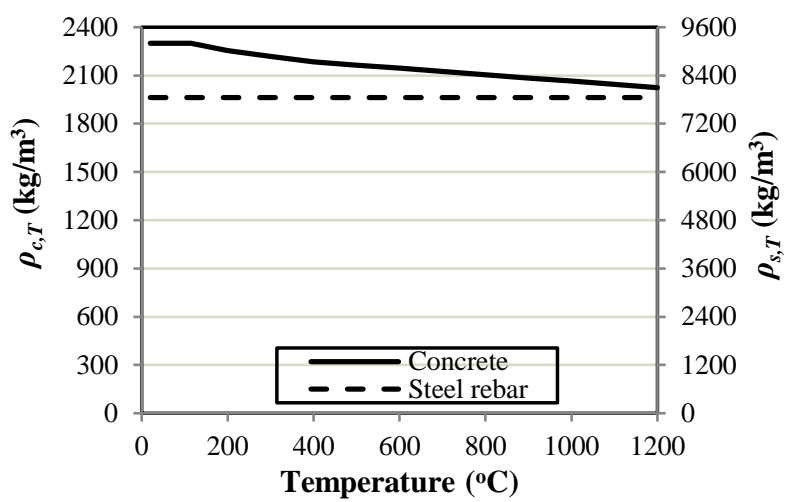

(c) Mass density

Fig. 2. Thermal properties at elevated temperatures of concrete (Eurocode 2 [21]) and steel rebar (Eurocode $3[22])$.

For the current study, concrete is modeled using the SOLID65 elements. The eight node SOLID65 element has three translational degrees of freedom in the nodal $\mathrm{x}, \mathrm{y}$ and $\mathrm{z}$ directions at each node. The element can be used for three dimensional modeling of concrete with or without reinforcement and can account for cracking of concrete in tension, crushing of concrete in compression, creep and large strains [15]. The steel rebar is modeled using the LINK180 elements, a uniaxial tension-compression element with three degrees of freedom at each node to account for translations in the nodal $\mathrm{x}, \mathrm{y}$, and $\mathrm{z}$ directions. The element is capable of modeling plasticity, creep, swelling, stress stiffening, and large deflections [15]. Note that in the proposed structural model the concrete and the steel rebar elements share the same nodes and the steel rebar occupies the same regions occupied by the concrete. A drawback of this model is that the concrete mesh is restricted by the location of the steel rebar and the volume of the steel rebar is not deducted from the volume of the surrounding concrete.

The material model for concrete of Williams and Warnke [31] is adopted for the current study. The shear transfer coefficients $\beta_{t}$ and $\beta c$ are taken as 0.2 and 0.7 , respectively [13]. The temperature-dependent mechanical properties of concrete and steel used in this study are taken from Eurocode 2 [21] and Eurocode 3 [22], respectively.

A multi-linear hardening model is implemented in ANSYS to accommodate the inelastic behavior of concrete at each temperature level. The material model is generated based on the strength reduction factors given by Eurocode 2 [21] for calcareous aggregates. The tensile strength of concrete is taken as $0.62 \sqrt{f_{c, T}}$ where $f_{c, T}$ is the compressive strength of concrete at temperature $T$ [7-8,13-14]. Once the concrete material reaches its tensile strength, a tensile stiffness multiplier of 0.6 is used to simulate a sudden drop of the tensile stress to $60 \%$ of the initial tensile rupture stress, followed by a linearly descending curve to zero stress at a strain value of six times the strain corresponding to the concrete rupture stress [18]. The variation of modulus of elasticity $E_{c, T}$, thermal strain $\varepsilon_{c, T}^{\text {th }}$ and compressive strength $f_{c, T}$ of concrete with temperature are shown in Fig. 3 while the Poisson's ratio of concrete $v_{c}$ is taken to remain constant at 0.2 . 


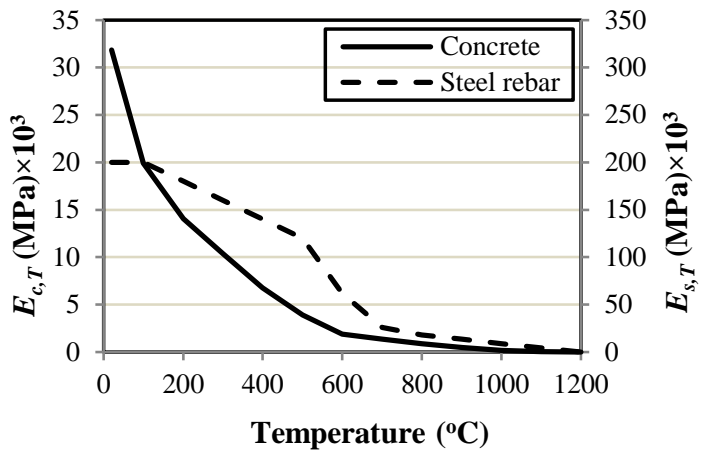

(a) Modulus of elasticity

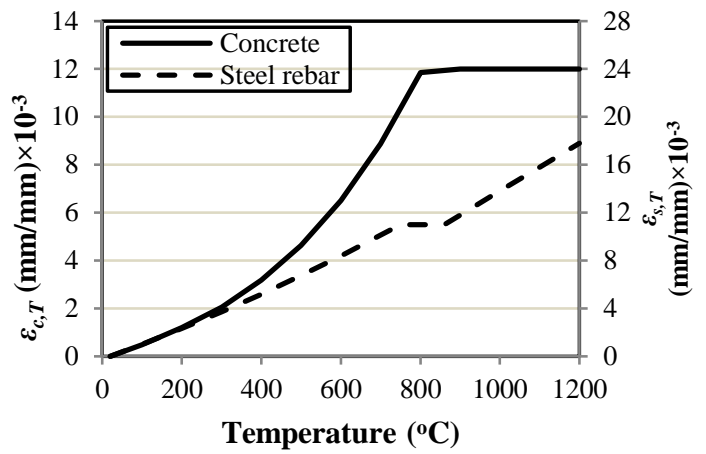

(b) Thermal strain

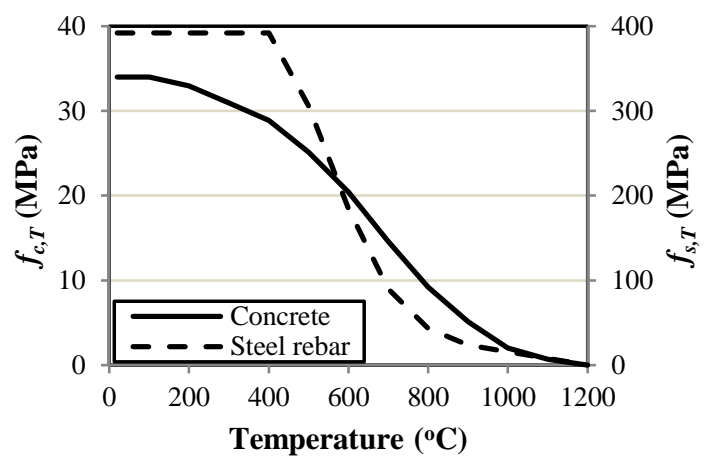

(c) Compressive/yield strength

Fig. 3. Mechanical properties of concrete and steel rebar at elevated temperatures.

The steel rebar is assumed to behave as an elasto-plastic material both in tension and compression. The multi-linear stress-strain relation is implemented herein by considering the modulus of elasticity of steel rebar as the initial tangent modulus of the stress-strain curve [18]. The temperature-dependent mechanical properties of steel rebar specified as input in the structural model are modulus of elasticity $E_{s, T}$, thermal strain $\varepsilon_{s, T}^{\text {th }}$, yield strength $f_{s, T}$, and Poisson's ratio $v_{s}$. The variation of modulus of elasticity, thermal strain and yield strength of steel rebar with temperature are shown in Fig. 3, while the Poisson's ratio remains constant at 0.3 .

\section{Description of the Fire Tests}

Load-bearing fire tests were carried out on two walls W1 and W2 having a length $l_{w}=3.42 \mathrm{~m}$, height $h_{w}=2.65$ $\mathrm{m}$ and thickness $t_{w}=0.12 \mathrm{~m}$ [16]. The details of the wall specimens are shown in Fig. 4. Each wall is reinforced with four equally spaced $12 \mathrm{~mm}$ steel deformed bars in the vertical direction and a $250 \mathrm{~mm} \times 250 \mathrm{~mm}$ grid of $8 \mathrm{~mm}$ deformed bars at the middle of the wall thickness. At normal temperature, the tensile strength of the $12 \mathrm{~mm}$ and $8 \mathrm{~mm}$ rebars were $392 \mathrm{MPa}$ and $540 \mathrm{MPa}$, respectively, while the compressive strength of concrete at 28 days was $43 \mathrm{MPa}$ for wall $\mathrm{W} 1$ and $44 \mathrm{MPa}$ for wall W2. Concrete mixtures with a water-cement ratio of 0.41 used to cast the walls W1 and W2, contain PP fibers in the proportion of $0.05 \%\left(0.45 \mathrm{~kg} / \mathrm{m}^{3}\right)$ and $0.2 \%\left(1.8 \mathrm{~kg} / \mathrm{m}^{3}\right)$ by volume, to prevent concrete spalling that may occur on the exposed face of these walls during the fire test. The walls are installed with dowel connections to the upper and lower cross beams to replicate an actual installation method used in high-rise buildings. Steel plates are used to connect the upper and lower cross beams to the furnace as shown in Fig. 4.

The axial load on each concrete wall was specified as $408 \mathrm{kN}$ (10\% of the buckling capacity of the wall at normal temperature and determined according to ACI 318 [32]). The prescribed axial load was determined considering the limitations of the fire test facility. The loading process is shown in Fig. 5.

In order to measure the temperature distribution throughout the wall during the fire test, 45 type-K thermocouples were installed with 9 thermocouples in a vertical plane, along 5 vertical planes through the wall thickness, as shown in Fig. 6. The vertical deflections of the concrete wall were recorded using two linear variable differential transducers (LVDTs) with a measurement range of $\pm 50 \mathrm{~mm}$, while the horizontal displacements of the wall were monitored using five LVDTs with a measurement range of $\pm 200 \mathrm{~mm}$ as 
shown in Fig. 7. The vertical and horizontal displacements of the wall were monitored throughout the course of the fire test considering the limiting deflection criteria of ISO 834-1 [17]. In addition, photographs of the unexposed face of the wall were taken to observe the crack patterns.

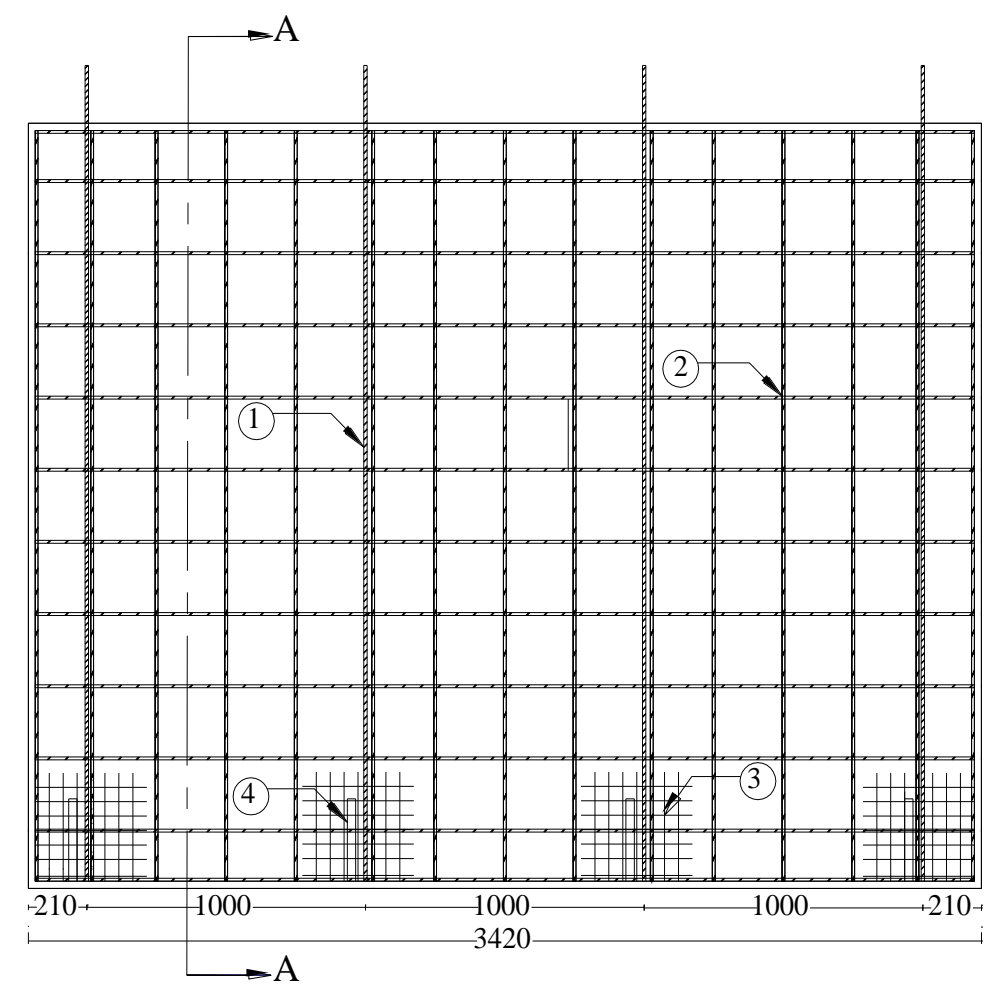

Transverse section
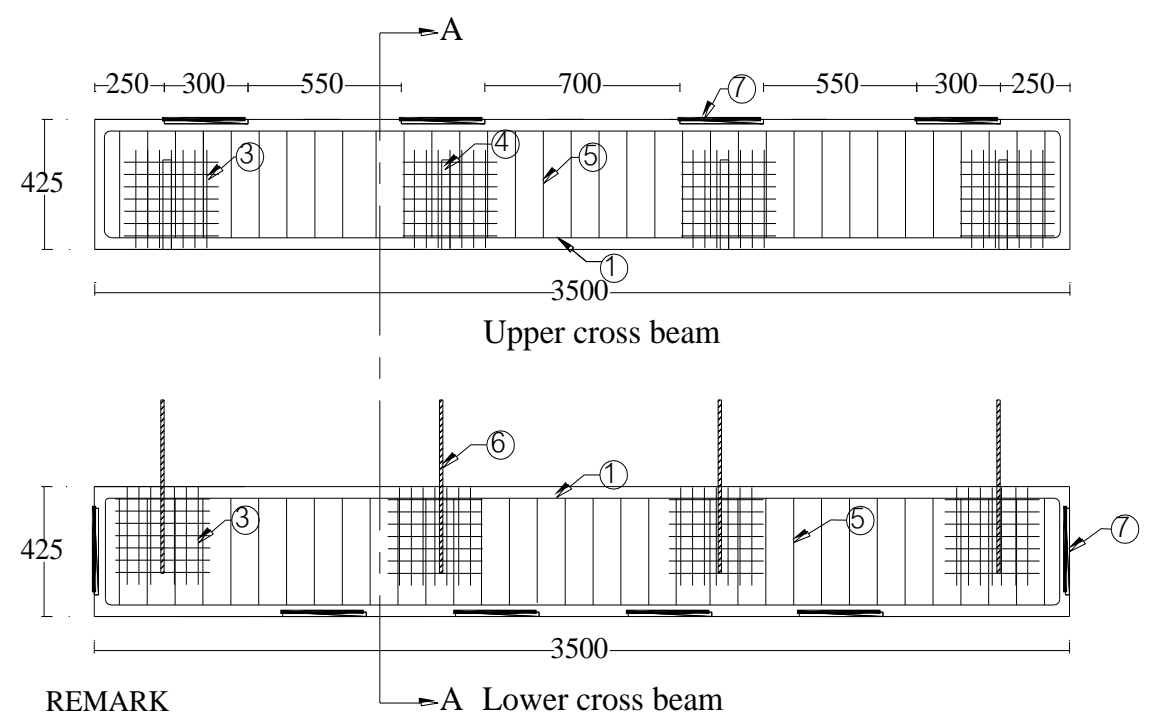

REMARK

(1) Steel rebar DB12 mm

(2) Grid bar DB8 @ $250 \mathrm{~mm}$

(3) Wire mesh Ø4 mm @100 mm

(4) Corrugate duct $\varnothing 50 \mathrm{~mm}$

(5) Stirrup DB12 mm @ 100 mm

6) Dowel bar DB12 mm

(7) Steel plate $300 \times 300 \times 15 \mathrm{~mm}$

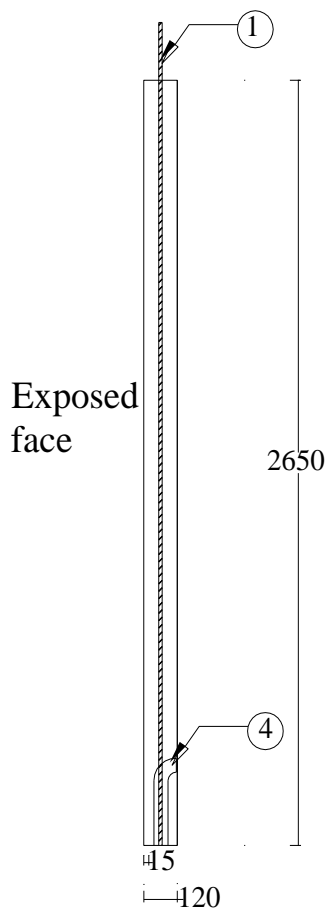

Cross section A-A

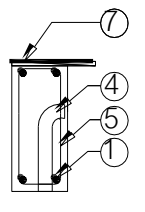

$-200 \longmapsto 100$

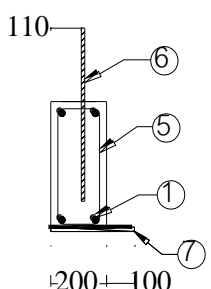

Cross section A-A

Unit: mm

Fig. 4. Details of wall specimens W1 and W2 [16]. 


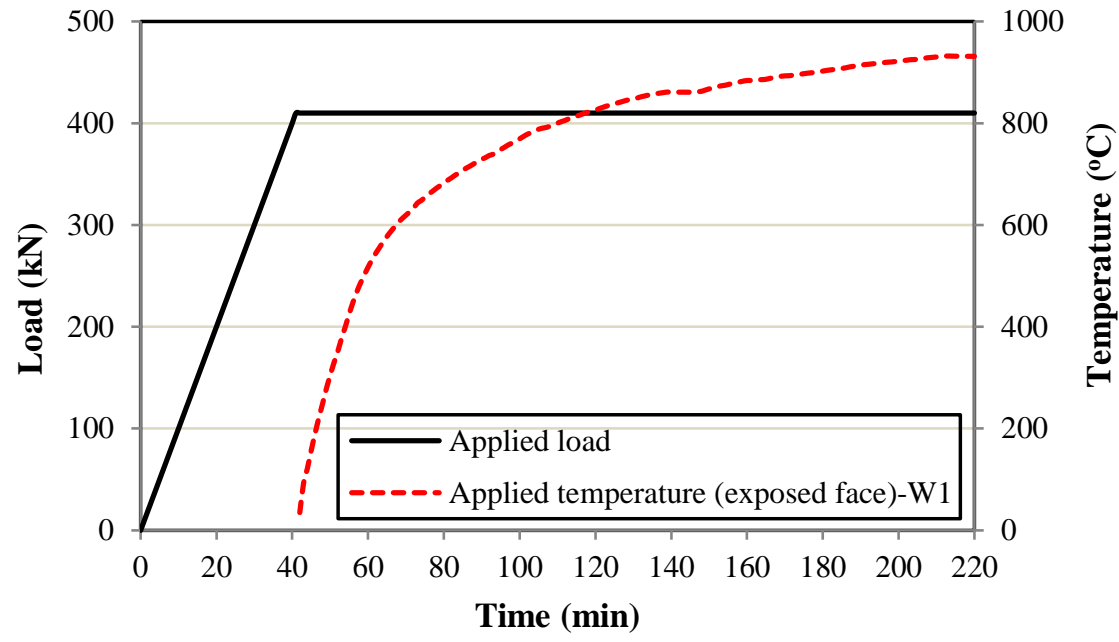

Fig. 5. The process of loading [16].
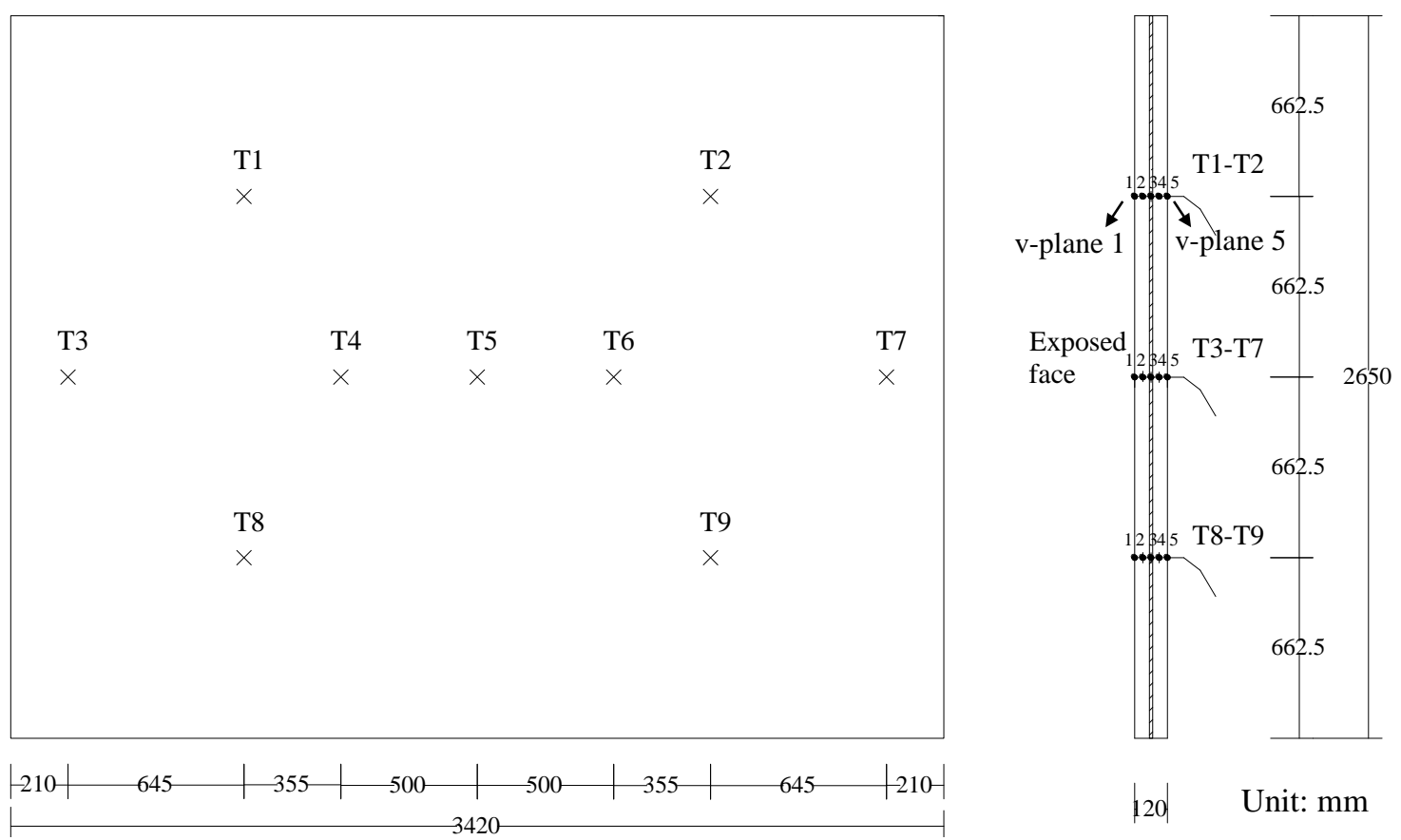

Fig. 6. Location of thermocouples [16].

\section{Validation of Precast Concrete Load-Bearing Wall 3-D Model}

\subsection{Thermal Response of Precast Concrete Walls}

The thermal model is validated by comparing the computed temperatures with the measured temperatures obtained from the fire tests conducted by Pothisiri et al. [16], temperature data taken from previous studies in the literature [33 - 34], and Eurocode 2 [21].

\subsubsection{Validation with temperature history from the fire tests}

The computed and measured temperatures along 5 vertical planes (referred to as v-plane) of the walls W1 and W2 are plotted in Fig. 8. The measured temperature is shown as the average of the nine thermocouple readings in each vertical plane (Fig. 6). Note that the exposed surface (i.e., v-plane 1) temperatures are used as input temperatures in the thermal model. 


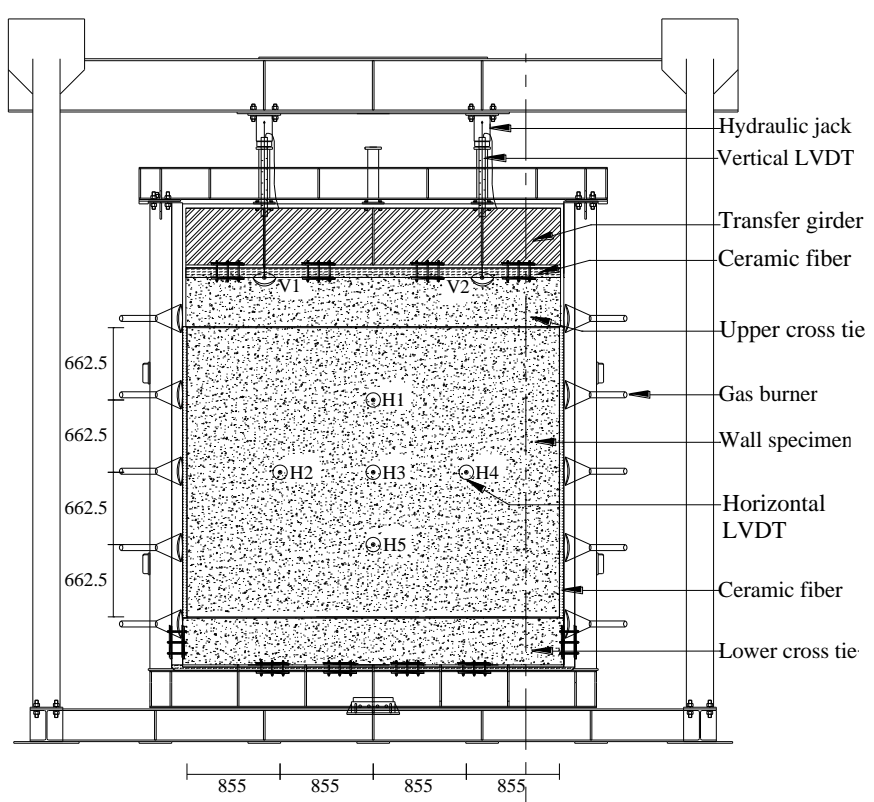

Fig. 7. Fire test setup and location of LVDTs [16].

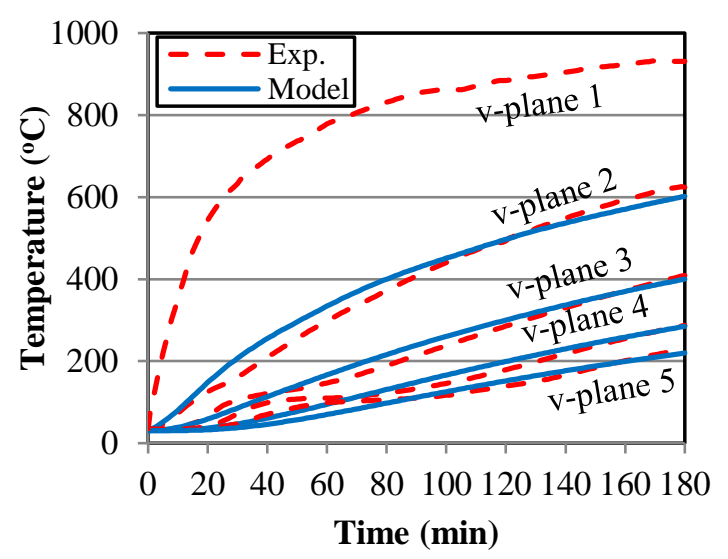

(a) W1

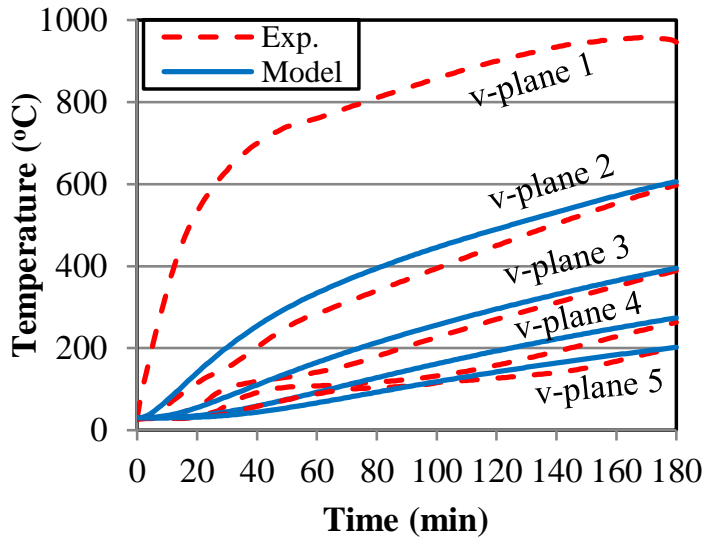

(b) W2

Fig. 8. Temperature history from fire tests of walls W1 and W2 along five vertical planes (here referred to as v-plane).

It is seen that the average temperatures in each vertical plane of the two walls are slightly different and increase with similar trends. However, the wall W2 shows lower temperatures in the inner vertical planes when compared with the wall W1. This is possibly due to the different thermal conductivity and specific heat of concrete in walls W1 and W2 resulting from the increase of PP fiber content in the concrete mixture of walls W2. The variation in thermal properties of concrete is not taken into account in the current study.

The temperatures predicted by the thermal model are in good agreement with those measured during the fire tests for both walls. Small discrepancies between the measured and the predicted temperatures are observed in the range of $20-50{ }^{\circ} \mathrm{C}$. The temperature deviation may be due to the thermal conductivity and specific heat of concrete mixed with PP fibers being different from those specified by Eurocode 2 and Eurocode 3. Based on the temperature data, the thermal model provides reasonably accurate predictions through the wall thickness. As such, the proposed thermal model can be used to predict the temperatures within the precast concrete load-bearing walls exposed to fire.

\subsubsection{Validation with temperature history from previous studies}

In order to further examine the validity of the proposed thermal model, the predicted temperatures are compared with available measured temperatures from experimental studies on reinforced concrete slabs exposed to fire [33-34]. Lim et al. [33] conducted a fire test on a flat slab with length $3.3 \mathrm{~m}$, width $4.3 \mathrm{~m}$ and 
thickness $0.1 \mathrm{~m}$. The slab was subjected to fire on the bottom side for $180 \mathrm{~min}$. The temperatures were recorded at 5 different horizontal planes, i.e. $0,25,50,75$ and $95 \mathrm{~mm}$ from the exposed face of the slab. Another fire test has been conducted by Lie and Williams-Leir [34] on a slab with length $0.9 \mathrm{~m}$, width $0.8 \mathrm{~m}$ and thickness $0.15 \mathrm{~m}$. The slab was subjected to fire on the bottom side for $360 \mathrm{~min}$ and the temperatures were recorded at the exposed face, mid-thickness and unexposed face of the slab.

Note that the thermal properties of concrete and steel rebar based on Eurocode 2 and Eurocode 3 are adopted for the finite element model. The predicted temperatures and measured temperatures for these two fire tests are shown in Fig. 9. The maximum deviations are found to be around $35{ }^{\circ} \mathrm{C}$ at the mid-thickness for Lim et al. [33] and $40{ }^{\circ} \mathrm{C}$ at the unexposed face for Lie and Williams-Leir [34]. Therefore, the proposed finite element model can be considered to be reliable for predicting temperatures of reinforced concrete slabs exposed to fire.
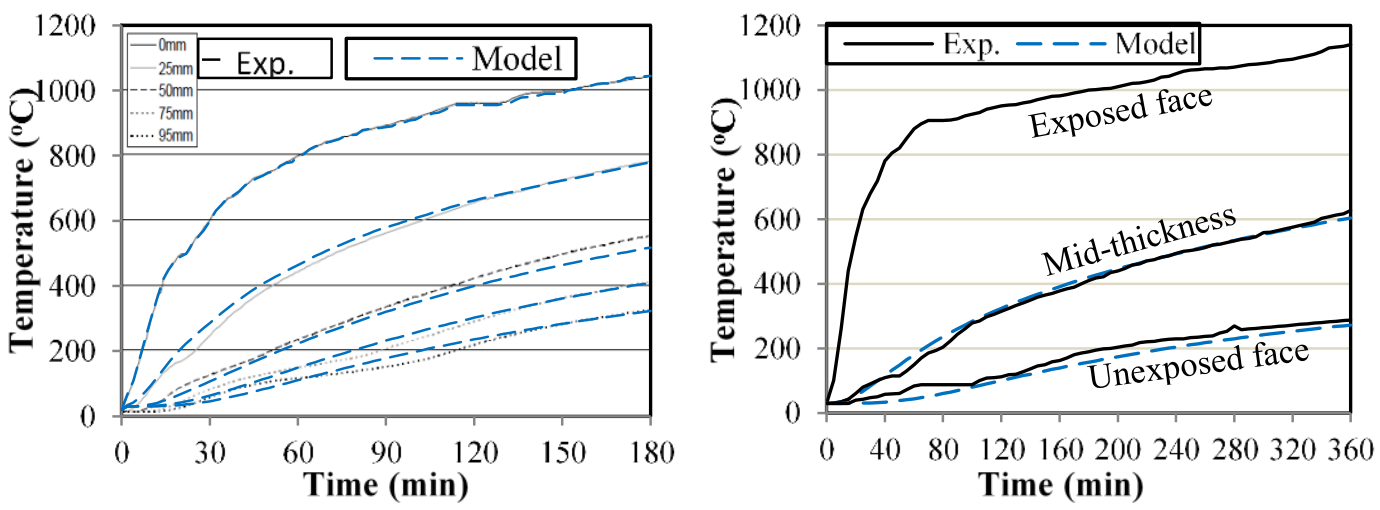

(a) Experimental results of Lim et al. [33] $\quad$ (b) Experimental results of Lie and Williams-Leir [34]

Fig. 9. Comparison between predicted and measured temperatures of RC slabs from previous studies.

\subsubsection{Validation with temperature profiles from Eurocode 2}

The proposed thermal model is also validated by comparing with the temperature profiles for slabs available in Eurocode 2 [21], which is also applicable for walls exposed to fire on one side (Fig. A.2, Eurocode 2 [21]). The temperature profiles for a wall with thickness $t_{w}=200 \mathrm{~mm}$ for standard fire exposures ranging from 30 min (R30) to 240 min (R240) are shown in Fig. 10.

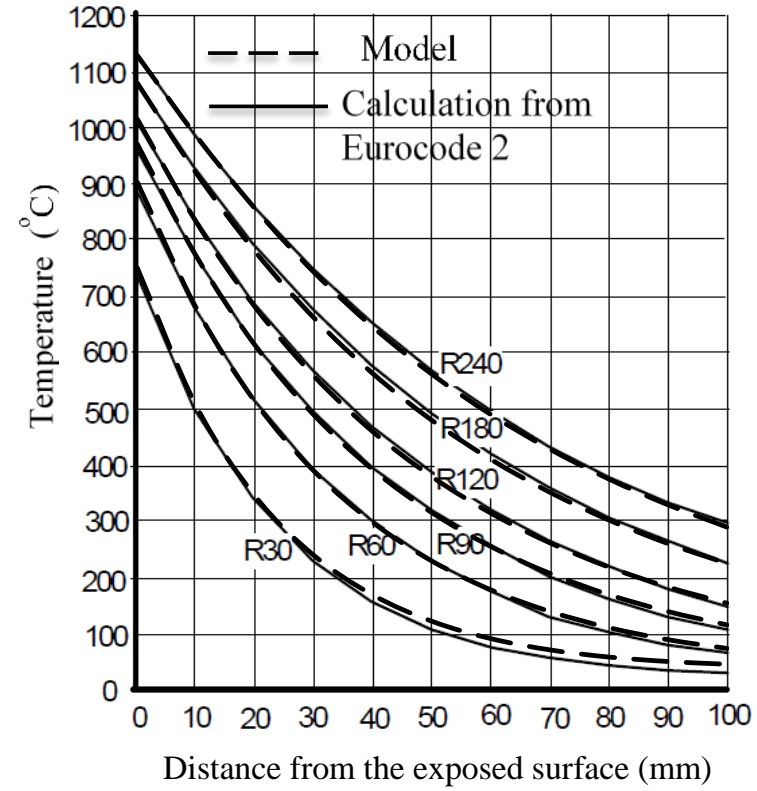

Fig. 10. Temperature profiles for the slap depth of $100 \mathrm{~mm}$ (total depth of $200 \mathrm{~mm}$ ). 
The predicted temperature profiles from the proposed thermal model are in good agreement with those calculated from Eurocode 2 [21]. The maximum deviation of the temperature is about $10^{\circ} \mathrm{C}$ for the fire exposure of R30 while the predicted temperature for other fire exposure levels shows good agreement with the calculated temperature from Eurocode 2 [21].

\subsection{Structural Response of Precast Concrete Load-Bearing Walls}

The wall is considered to have no rotational restraints at both ends of the wall (i.e., pinned at bottom end and simply supported at the top end). The structural model is validated by comparing the computed displacements and crack patterns with the results from the fire tests conducted by Pothisiri et al. [16].

\subsubsection{Comparison of displacements}

The computed horizontal displacements obtained from the structural model are compared with those measured during the fire tests as illustrated in Figs. 11 and 12. It is seen that the maximum horizontal displacements of the wall W1 as predicted by the structural model, match well with the measurements taken throughout the fire test. However, the structural model overestimates the horizontal displacements of the wall W2 when compared with the test results after the first $20 \mathrm{~min}$, with a maximum deviation of around 7 $\mathrm{mm}$. Note that the LVDT at H1 malfunctioned after $88 \mathrm{~min}$ from the initiation of the fire test and measured data is only shown up to that instant. Based on the above comparison, it can be concluded that the structural response obtained by the proposed model is reasonably accurate.

\subsubsection{Comparison of crack patterns}

Crack patterns obtained from the fire test are compared with the crack patterns obtained from the finite element model for the walls W1 and W2 in Figs. 13 and 14, respectively. In the finite element simulations when the principal stress exceeds the tensile strength of concrete, the crack plane is indicated by a straight line perpendicular to the principal stress direction.

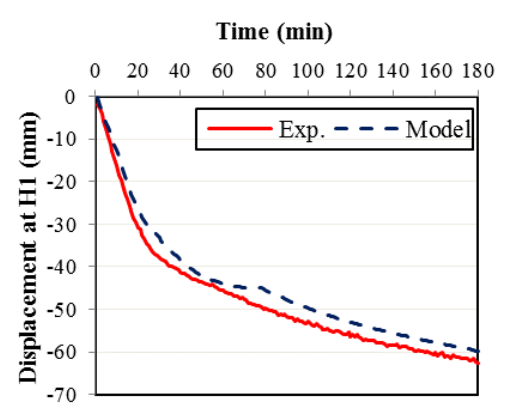

(a) $\mathrm{H} 1$

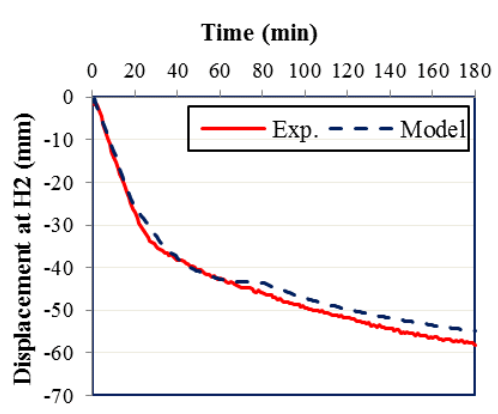

(b) $\mathrm{H} 2$
Time (min)

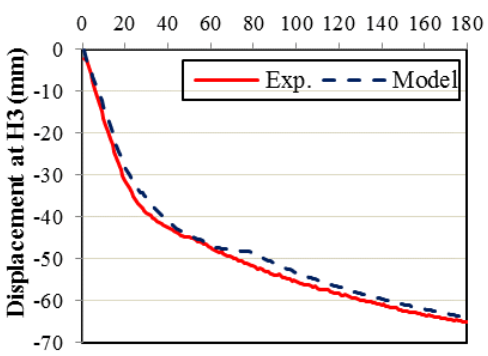

(c) $\mathrm{H} 3$

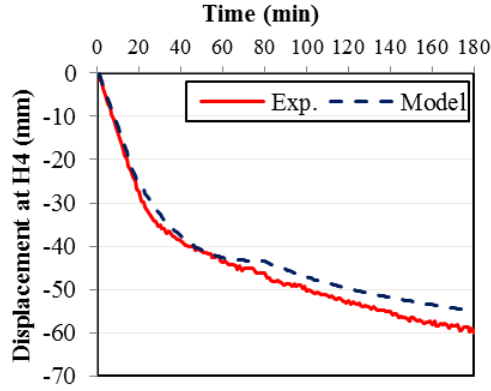

(d) $\mathrm{H} 4$

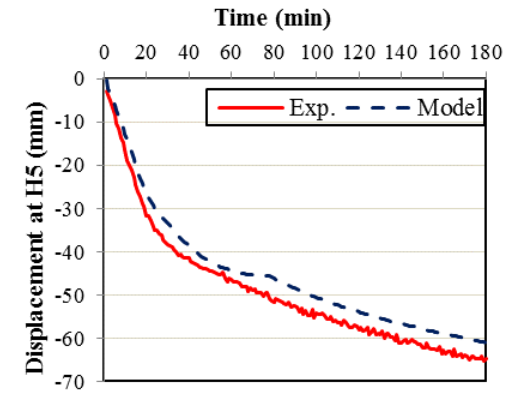

(e) $\mathrm{H} 5$

Fig. 11. Horizontal displacement of wall W1 at locations H1-H5. (The location of the horizontal LVDTs are shown in Fig. 7). 
Time (min)

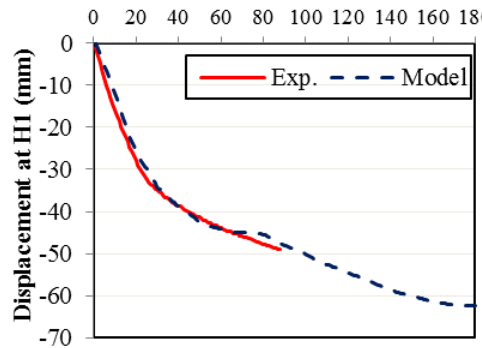

(a) $\mathrm{H} 1$
Time (min)

$\begin{array}{llllllllll}20 & 40 & 60 & 80 & 100 & 120 & 140 & 160 & 180\end{array}$

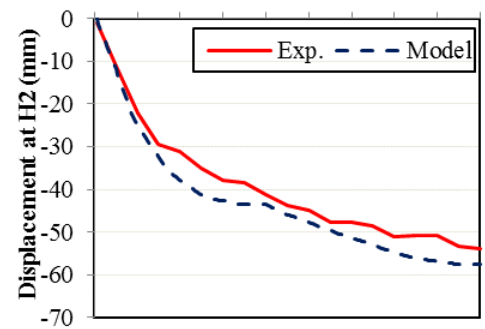

(b) $\mathrm{H} 2$
Time (min)

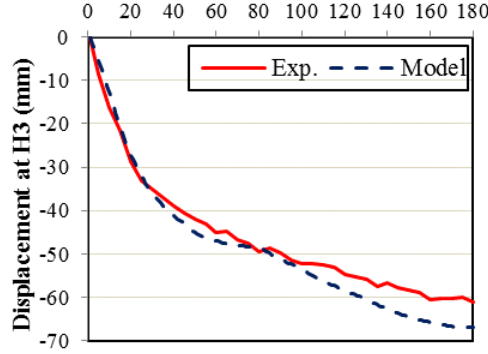

(c) $\mathrm{H3}$

Time (min)

$\begin{array}{llllllllll}0 & 20 & 40 & 60 & 80 & 100 & 120 & 140 & 160 & 180\end{array}$

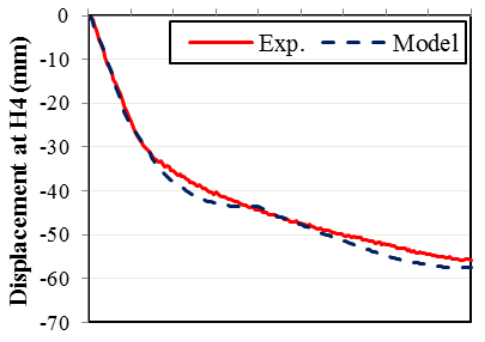

(d) $\mathrm{H} 4$

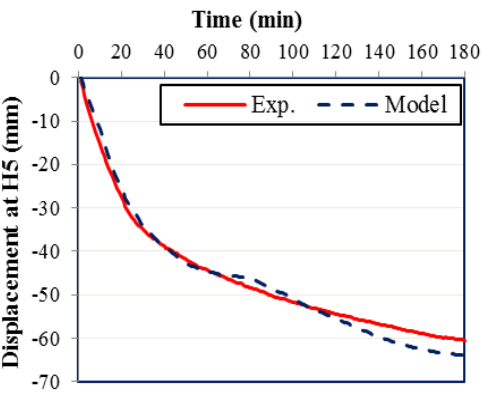

(e) $\mathrm{H} 5$

Fig. 12. Horizontal displacement of wall W2 at locations H1-H5. (The location of the horizontal LVDTs are shown in Fig. 7).

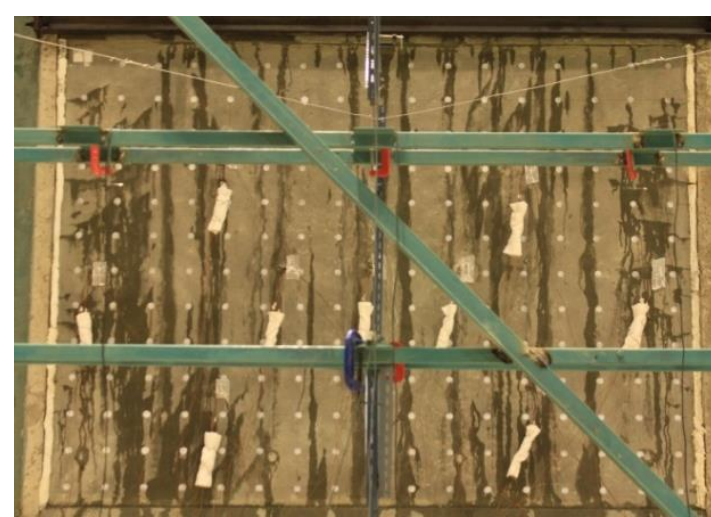

(a) Experiment [16]

Fig. 13. Crack pattern of wall W1.

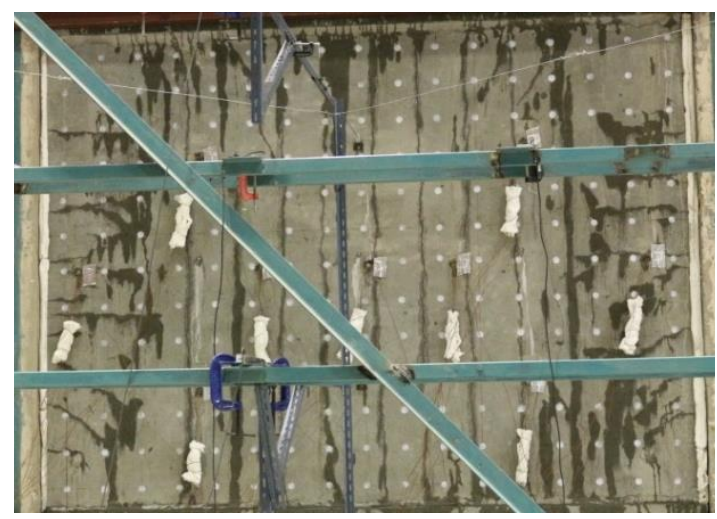

(a) Experiment [16]

Fig. 14. Crack pattern of wall W2.

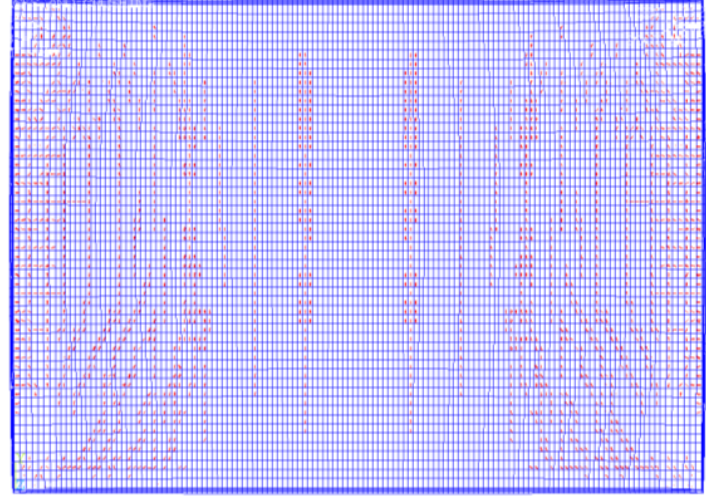

(b) 3-D finite element model

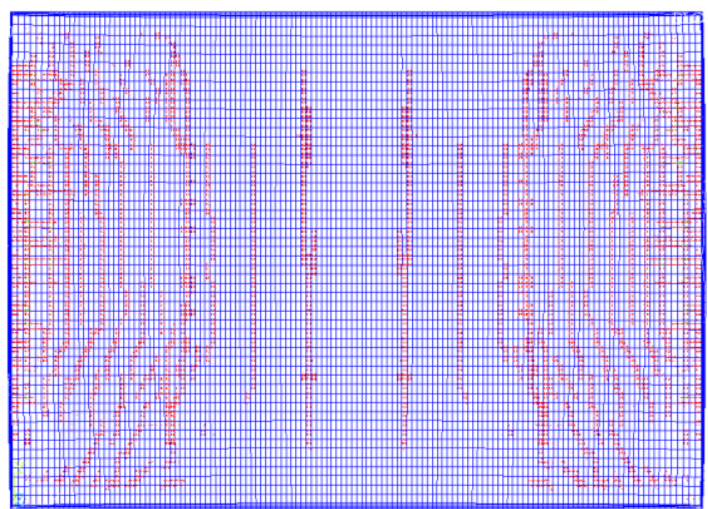

(b) 3-D finite element model 
It can be observed that the crack patterns of both walls as obtained from the proposed model are in line with the test results. The cracks on the unexposed face are initiated in the vertical direction at 17 min and 21 min for walls W1 and W2, respectively. The occurrence of these vertical cracks is mainly due to the thermal expansion of the wall in the horizontal direction with no restraints at the vertical edges. In addition, tensile stresses are induced in the horizontal direction as the load level is increased. Horizontal cracks in walls W1 and W2 are observed after 40-min and 43-min heating duration, respectively. The horizontal cracks are initiated near the vertical edges and propagate to the middle of the wall. In addition to the vertical and horizontal cracks, inclined cracks are also observed around the corners of the walls. The inclined cracks are initiated at about the same time as the horizontal cracks.

\section{Fire Performance of Load-Bearing Walls}

The finite element model validated in the previous section is used to examine the effect of load level, slenderness ratio and boundary conditions on the fire performance of precast concrete load-bearing walls. The input temperature used herein is the temperature of v-plane 1 in Fig. 8(a).

\subsection{Effect of Load Level}

The effect of varying load levels is investigated for a simply supported wall with length $l_{w}=3.42 \mathrm{~m}$, height $h_{p}=2.65 \mathrm{~m}$ and thickness $t_{p}=0.12 \mathrm{~m}$. The wall is subjected to axial loads that are $10 \%, 20 \%, 30 \%, 40 \%$ and $50 \%$ of the buckling capacity of the wall at normal temperature $(4,080 \mathrm{kN})$.

The mid-height horizontal displacement of the wall for different load levels is plotted in Fig. 15. The termination point of each curve indicates the time to failure of the load-bearing wall as obtained from the FE model. It can be seen that failure of the wall under the load levels of $0.2,0.3,0.4$ and 0.5 occurs at 170 min, $72 \mathrm{~min}, 33 \mathrm{~min}$ and $19 \mathrm{~min}$, respectively, while the wall does not fail under the load level of 0.1 within the heating duration of $180 \mathrm{~min}$. It is evident that the fire resistance rating of the load-bearing wall decreases by up to $90 \%$ with increasing load level. This is due to the fact that under the higher load levels, larger principal stresses are induced in the concrete elements which lead to earlier crushing failure. The 120 -mm thick precast concrete walls with a load level exceeding 0.2 are unable to sustain a 3-hour fire resistance period.

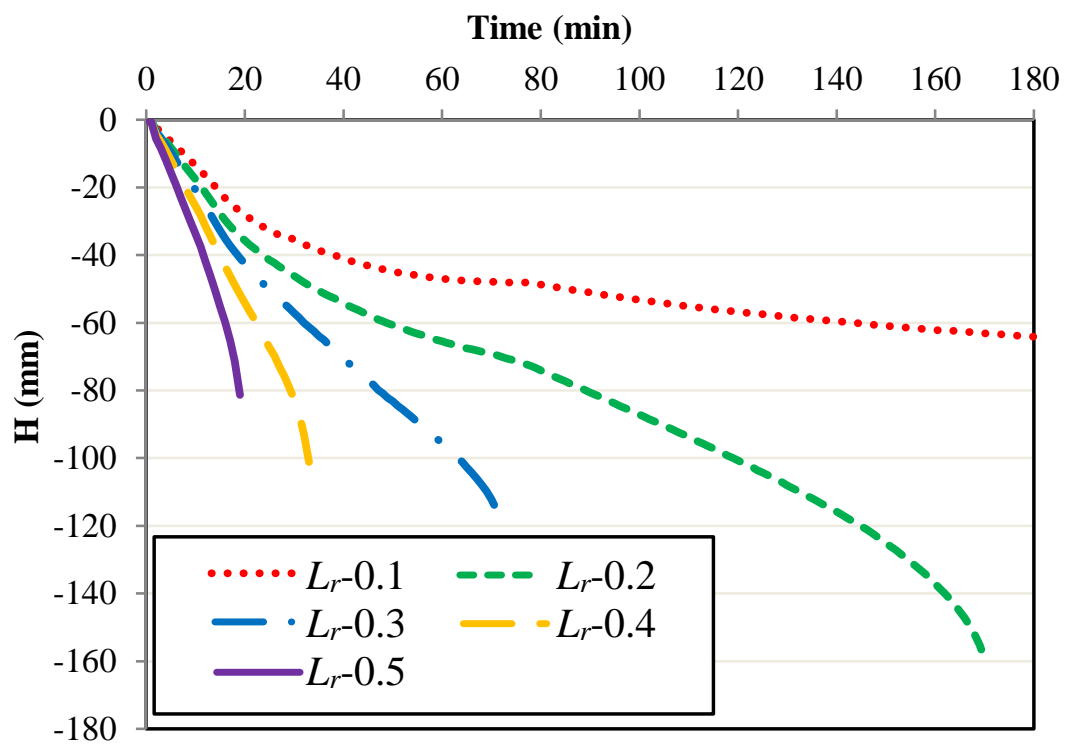

Fig. 15. Mid-height horizontal displacement of simply-supported precast concrete walls with varying load levels corresponding to axial loads that are $10 \%, 20 \%, 30 \%, 40 \%$, and $50 \%$ of the buckling capacity of the wall at normal temperature $(4,080 \mathrm{kN})$. 


\subsection{Effect of Slenderness Ratio}

In order to examine the effect of slenderness ratio on the fire performance of the precast concrete wall, a simply supported wall with length $h_{w}=3.42 \mathrm{~m}$ and thickness $t_{w}=0.12 \mathrm{~m}$ is considered. The wall height $h_{w}$ is varied to obtain different slenderness ratios $S_{r}=h_{w} / t_{w}$ of $20\left(S_{r}-20\right), 25\left(S_{r}-25\right), 30\left(S_{r}-30\right)$ and $35\left(S_{r}-35\right)$. These walls are subject to a constant axial load of $1000 \mathrm{kN}$ and are exposed to fire on one side.

The maximum horizontal displacements of the walls are shown in Fig. 16. It is seen that the walls with the slenderness ratios of 25, 30 and 35 have a fire resistance rating of 67, 26 and 12 min, respectively, while the wall with the slenderness ratio of 20 does not fail within the heating duration of $180 \mathrm{~min}$. This clearly indicates that walls with higher slenderness ratios are more prone to structural failure with lower fire resistance ratings by up to $93 \%$. Further, it is observed that the failure of the wall is primarily due to buckling as evident from the maximum stress and deflection along the wall height [35]. The failure criteria of Willam and Warnke [31] indicates crushing of concrete occurs only for the wall with the slenderness ratio of 25 . Meanwhile, for the other two walls with the slenderness ratios of 30 and 35, extremely large displacements are found at the mid-height where the maximum principal stresses are induced. The large displacements result in divergence of the finite element solution. As such, the walls can be regarded as reaching their load-bearing capacity, and the fire resistance rating can be determined.

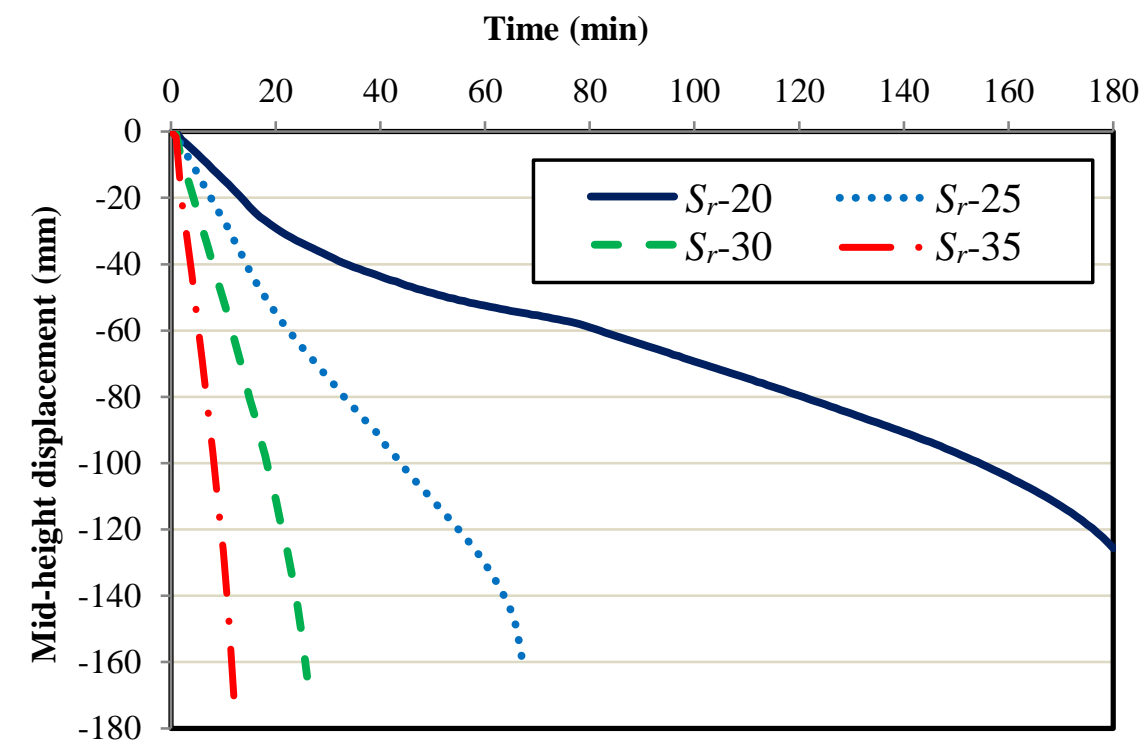

Fig. 16. Mid-height horizontal displacement of precast concrete load-bearing walls with varying slenderness ratios.

\subsection{Effect of Rotational Restraint}

The effect of rotational restraints on the fire resistance of load-bearing walls is examined for a wall with length $l_{w}=3.42 \mathrm{~m}$, height $h_{w}=2.65 \mathrm{~m}$, thickness $t_{w}=0.12 \mathrm{~m}$ and applied load of $2500 \mathrm{kN}$. The different boundary conditions considered are (a) SS: no rotational restraints at both ends of the wall, (b) FS: rotational restraints at the bottom end of the wall, (c) FF: rotational restraints at both ends of the wall (see Fig. 17). Note that in all cases the walls are allowed to translate vertically at the upper support with no axial restraint. The maximum horizontal displacement of the wall is shown in Fig. 18 and indicates that the rotational restraint has a significant influence on the fire resistance of load-bearing walls. The wall with no rotational restraints (SS) fails after $11 \mathrm{~min}$ of fire exposure, while the wall with rotational restraint at the bottom end (FS) fails after $129 \mathrm{~min}$. The wall with rotational restraints at both ends (FF) maintains its structural stability throughout the fire exposure period of $180 \mathrm{~min}$. This indicates that the fire resistance rating of the walls increases by up to $94 \%$ when rotational restraints are imposed at the ends of the walls. The positive effect of the rotational restraints on the fire resistance of load-bearing walls are due to the redistribution of positive and negative moments along the wall height [35]. 


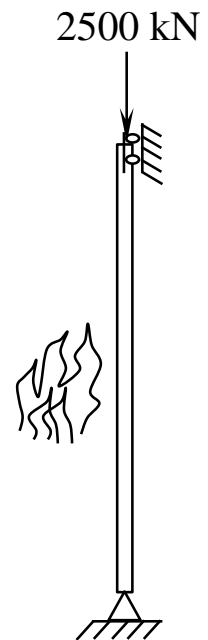

(a) SS

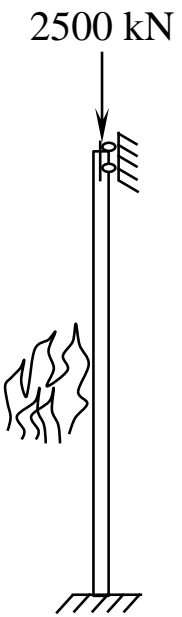

(b) FS

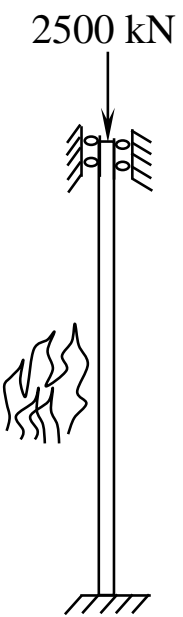

(c) FF

Fig. 17. Load-bearing walls with different boundary conditions.

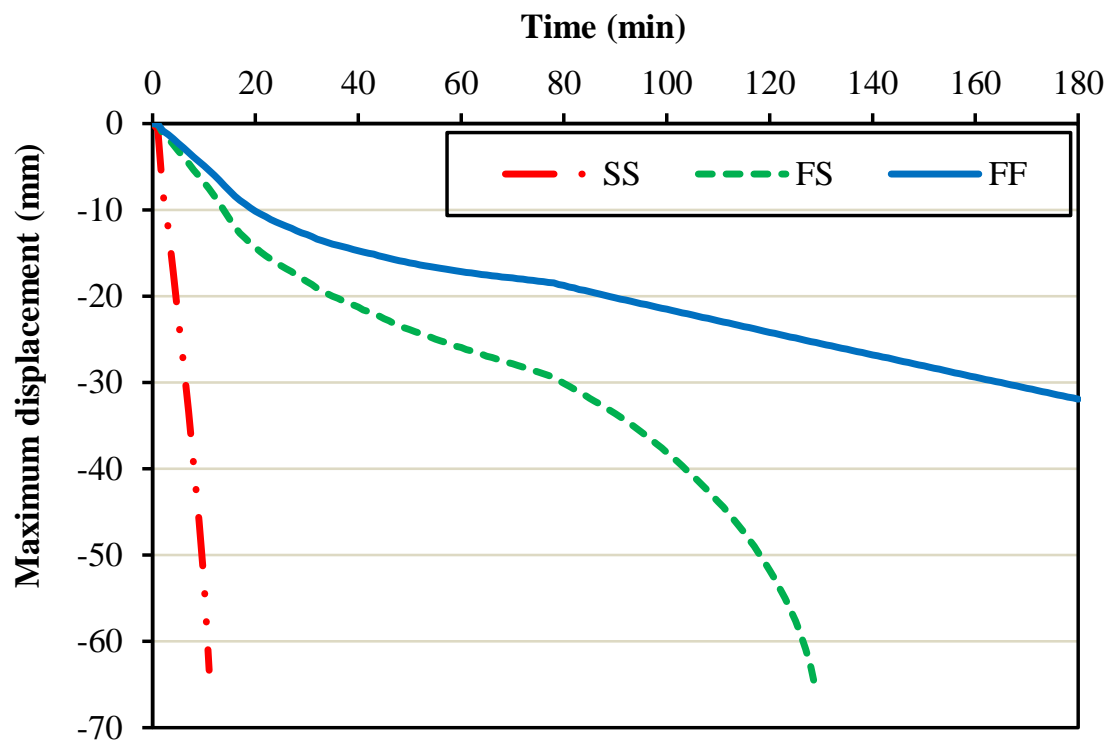

Fig. 18. Maximum horizontal displacement of load-bearing walls with different boundary conditions; SS: no rotational restraints at both ends of the wall, FS: rotational restraints at bottom end of the wall, FF: rotational restraints at both ends of the wall.

\section{Equations for Fire Resistance Rating (FRR)}

The fire resistance rating (FRR) of the precast concrete load-bearing wall is the fire resistance assigned to the wall on the basis of a test or some other approval system [20]. In this section, equations are derived for estimating the fire resistance rating of the precast concrete load-bearing walls in terms of load level $L_{r}$ and slenderness ratio $S_{r}$. The load level $L_{r}$ is defined as the ratio of the applied load to the load-carrying capacity of the wall at normal temperature.

The effect of varying boundary conditions is also included by examining the three cases SS, FS and FF mentioned in Sec. 5.3. The least-squares technique is used to determine the best fit of a third-order polynomial function to the dataset of fire resistance ratings obtained from the proposed model. However, to avoid the impact of varying thermal gradients, the equations are derived only for a wall with a thickness $120 \mathrm{~mm}$. It should also be noted that the equations are developed herein for the wall with a vertical reinforcement ratio of $0.30 \%$ and a compressive strength of concrete at normal temperature of $44 \mathrm{MPa}$. Furthermore, the effect of PP fibers on the thermal and mechanical properties of concrete is not taken into account due to the very small amount of PP fibers (0.05- $0.2 \%$ by volume) used in the concrete mixture. 
The fire resistance rating (FRR) for the three cases SS, FS and FF are plotted in Fig. 19, and the FRR is given by the following equations,

Wall with no rotational restraints at both ends of wall (SS):

$$
F R R_{S S}=1460-109 S_{r}-2560 L_{r}+4.25 S_{r}^{2}+4080 L_{r}^{2}-0.054 S_{r}^{3}-2170 L_{r}^{3}
$$

Wall with rotational restraints at bottom end of wall (FS):

$$
F R R_{F S}=1820-137 S_{r}-2420 L_{r}+5 S_{r}^{2}+3500 L_{r}^{2}-0.06 S_{r}^{3}-1720 L_{r}^{3}
$$

Wall with rotational restraints at both ends of wall (FF):

$$
F R R_{F F}=600-22 S_{r}-1370 L_{r}+0.86 \mathrm{~S}_{r}^{2}+1700 L_{r}^{2}-0.011 S_{r}^{3}-740 L_{r}^{3}
$$

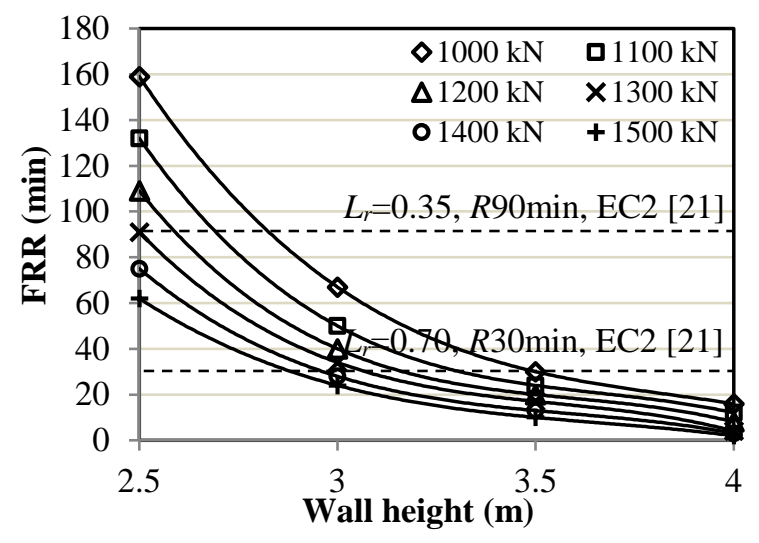

(a) SS

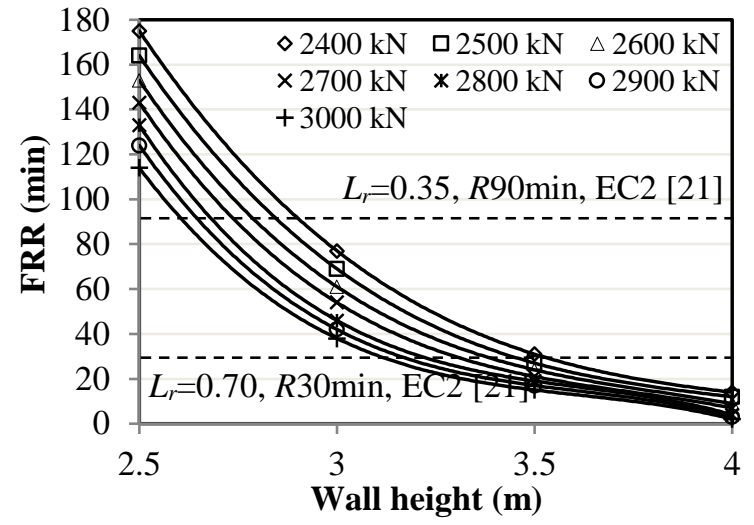

(b) FS

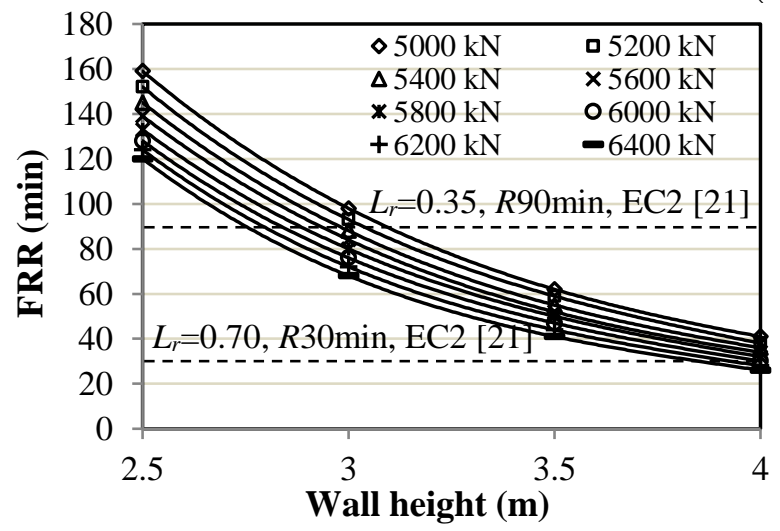

(c) $\mathrm{FF}$

Fig. 19. FRR of the walls obtained by using the finite-element model with varying heights and applied loads.

The overall fire resistance rating of the wall with rotational restraints at the bottom end of the wall is higher compared with the wall with no rotational restraints at both ends of the wall. The wall with rotational restraints at both ends of the wall provides a better fire resistance rating overall compared with the other two cases.

Also shown in Fig.19 is the FRR values for a 120-mm thick wall given by Eurocode 2 [21] at 90 min and $30 \mathrm{~min}$ for the load levels of $35 \%$ and $70 \%$, respectively. It is clearly seen that neither the effect of wall slenderness nor rotational restraint were taken into account in the codified FRR.

\section{Conclusions}

The fire performance of precast concrete load-bearing walls with varying load levels, slenderness ratios and boundary conditions has been investigated by using three-dimensional thermal and structural models. The models are verified against experimental data by comparing the predicted temperatures, displacements and crack patterns with the measured ones from fire tests.

Based on the modeling results, it is found that the temperatures predicted by the thermal model are in good agreement with those measured during the fire tests of the wall specimens W1 and W2, as well as those taken from previous studies of reinforced concrete slabs. The slight temperature deviation may be caused by 
variation of the actual thermal conductivity and specific heat of concrete from those specified by the Eurocode.

The predicted horizontal displacements are compared with those measured during the fire tests of walls W1 and W2. It is found that the maximum horizontal displacements of the walls as predicted by the structural model match well with the measurements taken throughout the fire test. Moreover, the crack patterns of the walls obtained from the proposed model are in good agreement with the crack patterns recorded during the fire tests.

The verified model is used to examine the effects of load level, slenderness ratio and boundary conditions on the fire performance of the walls. The results show that the fire resistance rating of the load-bearing wall decreases with increasing load level. This is due to the fact that under higher load levels, larger principal stresses are induced in the concrete elements, which lead to earlier crushing failure. It is also observed that walls with higher slenderness ratios are more prone to structural failure with lower fire resistance ratings. The failure of the wall is primarily due to buckling. In terms of boundary conditions, it is seen that the rotational restraint has a significant influence on the fire resistance of the load-bearing walls through the redistribution of positive and negative moments along the wall height. It is noted that the effects of load level, slenderness ratio, and rotational restraint on the fire performance of walls, are in line with the previous findings of other researchers.

Equations have been derived for estimating the fire resistance rating of the walls with different support conditions. These equations can be useful for the structural design of precast concrete load-bearing walls for fire safety.

The 3-D thermal and structural models proposed in this study can serve as an efficient alternative to extensive experimental studies, when investigating the fire performance of precast concrete load-bearing walls.

\section{Acknowledgments}

This research was supported by the "Chulalongkorn Academic Advancement into Its $2^{\text {nd }}$ Century Project", Chulalongkorn University.

\section{References}

[1] C. G. Go, J. R. Tang, J. H. Chi, C. T. Chen, and Y. L. Huang, "Fire-resistance property of reinforced lightweight aggregate concrete wall," Constr. Build. Mater., vol. 30, pp. 725-733, 2012.

[2] V. R. Munukutla, "Modelling fire performance of concrete walls," Civil Engineering Research Report 89-5, University of Canterbury, New Zealand, 1989.

[3] A. Damian, D. A. Crozier, and J. G. Sanjayan, "Tests of load-bearing slender reinforced concrete walls in fire," ACI Struct. J., vol. 97, pp. 243-253, 2000.

[4] A. J. O'Meagher and I. D. Bennetts, "Modelling of concrete walls in fire," Fire Safety J., vol. 17, pp. 315335, 1991.

[5] S. Lee and C. Lee, "Fire resistance of reinforced concrete bearing walls subjected to all-sided fire exposure," Mater. Struct., vol. 46, pp. 943-957, 2013.

[6] L. Lim, "Stability of precast concrete tilt panels in fire," Fire Engineering Research Report 00/8, School of Engineering, University of Canterbury, New Zealand, 2000.

[7] R. A. Hawileh, M. Naser, W. Zaidan, and H. A. Rasheed, "Modeling of insulated CFRP-strengthened reinforced concrete T-beam exposed to fire,” Eng. Struct., vol. 31, pp. 3072-3079, 2009.

[8] R. A. Hawileh and M. Z. Naser, "Thermal-stress analysis of RC beams reinforced with GFRP bars," Compos. B Eng., vol. 43, pp. 2135-2142, 2012.

[9] Z. Huang, "The behavior of reinforced concrete slabs in fire," Fire Safety J., vol. 45, pp. 271-282, 2010.

[10] S. Seręga, "Effect of transverse reinforcement spacing on fire resistance of high strength concrete columns," Fire Safety J., vol. 71, pp. 150-161, 2015.

[11] P. Bamonte and F. L. Monte, "Reinforced concrete columns exposed to standard fire: Comparison among different constitutive models for concrete at high temperature," Fire Safety J., vol. 71, pp. 310 323, 2015.

[12] U. Bajc, M. Saje, I. Planinc, and S. Bratina, "Semi-analytical buckling analysis of reinforced concrete columns exposed to fire," Fire Safety J., vol. 71, pp. 110-122, 2015. 
[13] V. K. R. Kodur, M. Naser, P. Pakala, and A. Varma, "Modeling the response of composite beam-slab assemblies exposed to fire," J. Constr. Steel Res., vol. 80, pp. 163-173, 2013.

[14] A. Esam and K. Venkatesh, "An approach for evaluating the residual strength of fire exposed bridge girders,” J. Constr. Steel Res., vol. 88, pp. 34-42, 2013.

[15] ANSYS Inc., ANSYS Mechanical ADPL Theory Reference, Ver 14.5. Canonsburg, PA, 2012.

[16] T. Pothisiri, S. Chou, and C. Sektheera, "Effect of polypropylene fibers and wire mesh on fire performance of precast concrete walls," ACI Struct. J., vol. 113, no. 2, pp. 393-403, 2016.

[17] Fire Resistance Tests - Elements of Buildings Construction, ISO834-1, General Requirements Part-1, International Organization for Standardization, Switzerland, 1999.

[18] E. Madenci and I. Guven, The Finite Element Method and Applications in Engineering Using ANSYS. Springer, 2007.

[19] J. M. Franssen, V. Kodur, and R. Zaharia, Designing Steel Structures for Fire Safety. CRC Press, 2009.

[20] A. H. Buchanan, Structural Design for Fire Safety. UK: Wiley, 2002.

[21] Eurocode 2 Design of Concrete Structures-Part 1-2: General Rules-Structural Fire Design, BS EN 1992-1-2, British Standards Institution, London, 2004.

[22] Eurocode 3 Design of Steel Structures-Part 1-2: General Rules-Structural Fire Design, BS EN 1993-1-2, British Standards Institution, London, 2005.

[23] J. Bošnjak, J. Ožbolt, and R. Hahn, "Permeability measurement on high strength concrete without and with polypropylene fibers at elevated temperatures using a new test setup," Cem. Concr. Res., vol. 53, pp. 104-111, 2013.

[24] C. G. Han, M. C. Han, and Y. S. Heo, "Improvement of residual compressive strength and spalling resistance of high-strength RC columns subjected to fire," Constr. Build. Mater., vol. 23, pp. 107-116, 2009.

[25] A. Bilodeau, V. K. R. Kodur, and G. C. Hoff, "Optimization of the type and amount of polypropylene fibres for preventing the spalling of lightweight concrete subjected to hydrocarbon fire," Cement Concrete Comp., vol. 26, pp. 163-174, 2004.

[26] T. Pothisiri and S. Chou, "Effects of mixing sequence of polypropylene fibers on spalling resistance of normal strength concrete," Engineering Journal, vol. 18, pp. 55-63, 2014.

[27] M. B. Dwaikat and V. K. R. Kodur, "A numerical approach for modeling the fire induced restraint effects in reinforced concrete beams," Fire Safety J., vol. 43, pp. 291-307, 2008.

[28] J. Xiao and H. Falkner, "On residual strength of high-performance concrete with and without polypropylene fibres at elevated temperatures," Fire Safety J., vol. 41, pp. 115-121, 2006.

[29] K. D. Hertz and L. S. Sørensen, "Test method for spalling of fire exposed concrete," Fire Safety J., vol. 40, pp. 466-476, 2005.

[30] A. Faris, A. Nadjai, G. Silcock, and A. Abu-Tair, "Outcomes of a major research on fire resistance of concrete columns," Fire Safety Journal, vol. 39, pp. 433-445, 2004.

[31] K. J. Williams and E. P. Warnke, "Constitutive model for the triaxial behavior of concrete," in Proceedings of International Association for Bridge and Structural Engineering, vol. 19, Paper III-1, ISMES, Bergamo, Italy, 1974.

[32] ACI Committee 318M-11, "Building code requirements for structural concrete (ACI 318m-11) and commentary," American Concrete Institute, Farmington Hills, Michigan, USA, 2011.

[33] L. Lim, A. Buchanan, P. Moss, and J. M. Franssen, "Numerical modelling of two-way reinforced concrete slabs in fire," Eng. Struct., vol. 26, pp. 1081-1091, 2004.

[34] T. Lie and G. Williams-Leir, "Factors affecting temperature of fire-exposed concrete slabs," Fire and Materials, vol. 3, pp. 74-79, 1979.

[35] S. Chou, "Numerical simulation of precast concrete load-bearing walls exposed to fire," Dissertation, Dept. of Civil Engineering, Chulalongkorn University, Thailand, 2014. 